\title{
Research on the Application of Illustrations in Modern Publications
}

\author{
Shui Jin * \\ School of Advertisement \\ Beijing Institute of Fashion Technology \\ Beijing, China \\ jinshui@126.com
}

\author{
Yanran Shang \\ China Publishing House \\ Beijing, China \\ 619998893@qq.com
}

\begin{abstract}
As an art form in modern publications, illustration is closely connected with people's reading. Especially at present, illustration plays an important role in print media. It is more and more closely related to the field of book publishing. With the development of illustration, its expression has become more and more diversified. In publication, illustration also gives the audience infinite fun because of its unique artistic infectivity. From the angle of publication illustration design, this paper will discuss in the aspects of expression style, technique, color and so on.
\end{abstract}

\section{Keywords-illustration; publication; form}

\section{INTRODUCTION}

Illustration is a form of expression of visual communication. Its powerful visual impact and artistic charm make people be attracted in a short time, and can effectively disseminate content and information. Therefore, it is increasingly becoming a part of people's life.

\section{CONCEPTS AND FEATURES OF ILLUSTRATION}

\section{A. Concept of Illustration[1]}

The illustration comes from Latin and it means to illuminate. Illustration, with a long history, is an art form of information communication in graphic language, and it is an appended picture made for words, which explains words more vividly. It has also played an important role in human social life from ancient to modern times. With its unique artistic charm, illustrations infect the viewer, allowing the viewer to experience the pleasure of art appreciation while reading the information. With the development of modern society, modern illustration has already broken through the limitation of being the foil of the words. It also has the functions of persuasion, guidance and illustration. It has a strong infectivity, not only to make the theme clearer, but also to increase the interest of the text.

Due to the wide application of illustration, it can be used in books, newspapers, magazines, advertisements, computers and other visual communication fields. Although it can strongly attract people's attention, most of them just stay on the surface, and they are not familiar with the art of illustration. They do not have a systematic understanding of its essential concepts, classification, style and application. In today's society, the extensive application of illustration gives us visual and spiritual enjoyment, and enriches our imagination and creativity.

\section{B. Features of Illustration}

Every art form is integrated with thoughts and feelings of the author, so the author will try his best to keep his own thoughts and feelings and creative styles in the commercial creation. Its purpose is to be able to combine aesthetic value with business.

The printing technology is developing with the progress of The Times. The appearance and wide application of digital technology today, make illustrations closely follow The Times and develop and change. Meanwhile, the contents of illustrations also present a variety of contents and forms with the development of The Times. It reflects the aesthetic trend of different times. At the same time, we believe that the reason why illustrations are generally accepted by the public is that they are very close to the public life and commercial illustrations are ultimately for using. Therefore, what illustrations show must be acceptable to the public and meet the psychological and aesthetic needs of the audience.

"It is precisely because the transmission of vision is direct that it must be connected to the mind on a deeper and more vivid level of experience than language," says Bella Barajas. According to a survey, twice as many people read illustrations and illustrations in print ads as read text. And when reading, people are always attracted by colorful images before turning to words. People pay attention to graphics and text respectively $78 \%$ and $22 \%$. It can be seen that the visual stimulation of various types of picture works is much higher than that of words. In an instant, illustrations can catch the eye of the audience. Vivid images, bright colors and interesting symbols are all factors that attract attention.

\section{Classification AND PRESENTAtion Style OF ILLUSTRATION IN MODERN PUBLICATIONS}

\section{A. Classification of Illustration in Modern Publications}

- Newspaper illustration. Newspapers are a traditional way of getting information in our lives. Newspapers are mainly news reports, and many words must be used in a large number of illustrations, which is an important carrier of illustration. At the same time, because of the wide spread and update speed of the newspaper, it also provides convenience for the spread of illustration. In 
the process of reading, prominent visual illustrations not only play a role in enriching the layout, but also help readers grasp the information of articles.

- Magazine illustration. Magazines provide a wide space for illustration design. Illustration is an indispensable part of journal magazines, and it usually used on the cover, back and inside of magazines. Especially in fashion magazines, fashion illustrations are more widely used. Magazines use much better paper than newspapers, which is also good for reading and looking at illustrations.

- Book illustration. Book illustration is mainly designed for book cover, format and text, which can be roughly divided into literary art, science and technology and children's book illustration. The illustration of literature and art books requires strict description according to the content of the book and accurate representation of the psychological activities of the characters. Scientific and technical illustrations can make the words more clear, accurate grasp and detailed description is the biggest characteristic of such illustrations. Children's book illustration should be created according to children's psychology, such as using exaggeration, personification techniques, plus bright colors, can make the picture become lively and imaginative.

\section{B. Presentation Style of Illustration in Modern Publications[2]}

As far as illustration itself is concerned, information communication is its main function and effect. However, without aesthetic value, artistic connotation and appeal, information communication cannot be achieved effectively. Its style is summarized as follows:

- Realistic style performance: the illustration form of realistic style is a popular kind of painting, that is, painting with relatively realistic techniques, which is very real. Today's realistic style illustrations are diverse and colorful. Illustrators use different tools to draw pictures, which make the realistic style show different features from the color: meticulous, simple, thick, or light, etc.

- Abstract style performance: abstract and concrete are opposite. The illustration creation of abstract style is based on imagination and creator's intuition. It is not like a realistic style that focuses on depicting objective objects. There is no concrete natural phenomenon in the picture of abstract style form, only pure figure and color are presented. Abstract style illustration is also a very popular form in illustration design.

- Cartoon style performance: cartoon image is very popular with children for its exaggerated and lovely image, so cartoon style becomes one of the indispensable expressions in painting art creation. With new style and painting techniques and the subject increasing, cartoons attract more and more audiences of all ages and promote the development of cartoon style. Compared with other creation styles, cartoon style is lively and lovely, and has a strong impact on eyeballs.
It is widely used in the field of illustration, especially in advertising and corporate image publicity.

- Decoration style performance: decoration is very formal and aesthetic. It is not to express real space, but to put things in flat space. Therefore, decoration style is full of imagination. Or when creating very simple things and not knowing how to deal with them, we can use flat language to decorate with color, size and direction to make the original rigid picture become vivid.

- National style performance: as the saying goes, national is the world. The use of ethnic style elements in illustration design can make the work full of local regional culture flavor. Because these patterns are highly symbolic and allegorical, adding them can well integrate the national cultural spirit into them and show the local characteristics. As a result, the entire illustration is featured with cultural and artistic flavor, which can effectively attract consumers.

- Exaggeration style performance: the exaggeration style is to use bold imagination to exaggerate the characteristics of the object without changing the basic form of the object. The illustrator delicately analyzes the features of the object's shape and size, and exaggerates its movements, expressions and parts according to the aesthetic principles. It is novel and strange without violating people's subjective experience, thus making the image more distinct and deeply rooted in people's hearts.

- Surrealism style performance: the expression style of surrealism is bold. It integrates the subjective intention of the illustrator into unreasonable structure and space to arouse the readers' curiosity. This form has strong visual and psychological impact. Surrealistic style is also derived from life. It only exaggerates the characteristics of things to achieve the emotion expressed by the author. For example, Ji Mi' picture books often use surreal techniques to create the artistic conception of loneliness and express the loneliness of the urban crowd.

\section{The Technical Form of Illustration in Modern PuBLICATIONS}

\section{A. Hand-drawn Illustration Techniques}

The manifestation of hand-drawn illustration is mainly to apply the traditional freehand painting in the field of commercial illustration. This technique has a variety of tools, including pencil, pen, print, ink, oil painting, acrylic painting, watercolor painting, color powder, oil stick, marker pen, color lead, paint and other painting tools.

Fashion illustration master David tang's works, fashion magazines and newspapers, use the form of hand-painted watercolor painting techniques, accurately grasp the human form, concise looming line and watercolor style capture the most feminine women mysterious side. Its natural style, as well as the perfect grasp of the composition, let him firmly stand in the world of fashion. 


\section{B. Digital Illustration Techniques}

Digital techniques is using computer graphics software to draw illustration works, with the progress of times and the development of science and technology, this form of illustration is more and more widely, computer drawing is easy to store, carry and transmission, and the color is rich, drawing tools is variety. The painter can also make his own work different effects. All of these provide convenient conditions for the creation of the representation form of digital illustration.

\section{Collage Illustration Techniques}

The main forms of collage techniques are hand collage and computer collage. Manual collage is to make some physical materials according to certain graphics, and then collage into a complete picture. Computer systems have developed the technique of "collage" by scanning images, slicing and pasting them seamlessly and then inserting them into an overall design, whose final visual complexity and high level of integration are beyond the reach of traditional media. Techniques are flexible and rich and they can be figurative or abstract. It could be twodimensional, or three-dimensional.

\section{Multi-media Illustration Techniques}

Nowadays, the single technique expression form has been increasingly unable to meet the requirements of illustration creators for their works, so many illustration designers effectively combine the forms of freehand painting, digital, photography, etc. to create new forms, which is also very novel. For example, it is very novel to compare the excellent effect of glasses on the face to the effect of finishing hair on the face by painting pictures in the field and using metaphor. The painting effect of realistic face painting is very expressive with glasses.

\section{E. Three-dimensional Illustration Techniques}

The manifestation of three-dimensional illustration is very novel and avant-garde. This technique is usually producing the real object first, then photographs it, and formats the text for the poster at last. Another way to do three-dimensional illustration is to simulate the effects of three-dimensional space on two-dimensional paper. This realistic simulation of three-dimensional space is also surprising. The common threedimensional illustrations are paper carving, clay sculpture, and so on. As shown in the picture, a three-dimensional paper art illustration creates a sense of three-dimensional space, which makes people feel fresh and new.

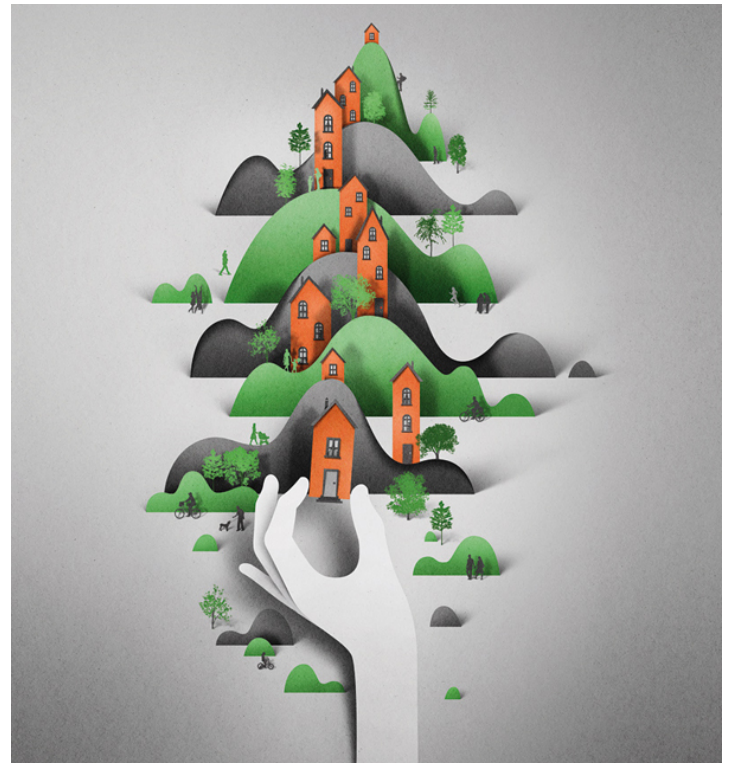

Fig. 1. Three-dimensional paper art illustration.

\section{COLOR REPRESENTATION OF ILLUSTRATION IN MODERN PuBlicAtions}

\section{A. Single Color Form}

Drawing illustration is only one color. This kind of illustration works often use the traditional print style expression, and has the traditional history feeling.

\section{B. Black and White Color Form}

Use only the form of black and white painting. Even if the lack of other forms of illustration so rich and diverse colors, they have unique, classic beauty of power. There is also the use of a single line, line - painted means to complete the illustration design.

\section{Comparison of Temperature Form}

We usually call the bright and vivid colors such as orange, red and yellow as warm colors, and the colors associated with grass, blue sky and snow as cool colors, such as green and blue. The contrast of warm and cold colors makes the picture stand out and attract people's attention.

\section{Complementary Color Contrast Form}

It is to use complementary color to show intense contrast color, such as red and green, yellow and purple, blue and orange, etc. This kind of color contrast expression should pay attention to the relation of color area contrast and the application of purity contrast, otherwise it will be backfire.

\section{E. Low Brightness Color Contrast Form}

Lightness refers to the degree of light and shade, white color lightness degree is the highest and black minimum. Between them is a series of different lightness of gray. in illustration images, using the color contrast, close brightness can make the whole picture soft, comfortable, harmonious, and make the illustration feast for the eyes. 


\section{F. High Brightness Color Contrast Form}

This group of illustrations used different color brightness of the same color, with a big difference in color brightness, which made it stand out among numerous packaging products. At the same time, they also had a strong regional flavor, which made people shine at the moment and generated the desire to buy.

\section{G. High Saturation Color Contrast}

Saturation refers to the purity of color. The saturation is lower when the proportion of gray, white, or other colors. Solid colors are highly saturated.

\section{H. Low Saturation Color Contrast}

The color purity can be reduced by adding multiple colors, and the use of low saturated colors can make the picture more harmonious and stable.

\section{CONCLUSION}

Nowadays, illustration is more and more popular among people. With the continuous innovation of society, illustration plays an irreplaceable role in modern publications. The field of illustration will continue to expand, the form will be more abundant, and the market will continue to improve and develop. To sum up, illustration has been more and more applied to modern publications, which undoubtedly bring a broader space for the development of publications. The relationship between illustration and text is mutual. Illustration enriches the expression "language" of publications. At the same time, the commercial value of illustration also needs publication to reflect.[3]

\section{REFERENCES}

[1] Diversified development of art design - Baidu Wenku Internet document resources (http://wenku.baidu.c),2012.

[2] Jin J. On illustration art in graphic design[J].China Packaging Industry,2014.

[3] Zhuo H L, The Influence of Illustration on Chinese Modern Graphic Advertisement Design[J].Yi Hai,2010. 